\title{
Mineraçãa
}

\section{Influência da durabilidade no comportamento geotécnico dos filitos da Mina Pau Branco}

\author{
Influence of slake durability on geotechnical \\ behavior of phyllites of Pau Branco Mine
}

\begin{abstract}
Carolina Helena Caldeira Silva
Mestre em Engenharia Mineral, DEMIN/UFOP

carolcaldeiras@hotmail.com
\end{abstract}

\section{Milene Sabino Lana}

Professora Associada da Escola de Minas, DEMIN/UFOP.

milene@demin.ufop.br

\section{Resumo}

Propõe-se, nesse trabalho, o estudo da influência da durabilidade no comportamento geotécnico das rochas do Talude Oeste da Mina Pau Branco, de propriedade da Vallourec \& Mannesman (V\&M) Mineração, localizada na serra da Moeda, no município de Brumadinho, Minas Gerais. No local, a ocorrência de fraturamento acentuado e de dobramentos, aliados ao clima regional, levou à formação de rochas com baixa resistência e elevados graus de alteração, fato que favorece mecanismos de instabilização. Foi avaliada a influência da durabilidade nas propriedades físicas dos filitos com graus distintos de alteração e resistência, através da realização de ensaios de durabilidade. Buscou-se, também, a partir do referido ensaio, identificar a existência de correlação entre a durabilidade e o modo de ruptura nos taludes em filitos, verificando, assim, se o referido índice pode ser utilizado como um indicador expedito do tipo de mecanismo de ruptura e da resistência do material. Os estudos incluíram, ainda, análises cinemáticas, para identificar condições para ocorrência de rupturas, segundo descontinuidades existentes no talude, e comparar tal ocorrência a rupturas observadas em campo. Para tal foi utilizado o software Dips5.0, da Rocsciense, Canadá.

Palavras-chave: Índice de durabilidade, mecanismos de ruptura, parâmetros de resistência.

\begin{abstract}
This paper discusses the durability's influence on the geotechnical behavior of the West Slope's rocks of Pau Branco Mine, this being the mining site on Vallourec \& Mannesman (V\&M) property, located at Serra da Moeda, Brumadinho, Minas Gerais. At the site, the occurrence of acute fracturing and folding of the rocks, plus the effects of the local weather conditions, were responsible for forming low mechanical strength and high alteration grade rocks, favoring destabilization mechanisms. The influence that durability has on the phyllite's physical properties was evaluated through slake durability tests with different alteration grade and strength phyllites. Through the same tests, an attempt was made to identify the existence of an association between the durability and the failure mode in phyllite's slopes. This correlation was important to be found because it could be used as an expeditious indicative of the failure mechanism and the strength of the lithologies that exist in the slope studied. Furthermore, these studies included kinematic analysis to identify conditions for the occurrence of failures caused by discontinuities and to compare these failures to the ones observed at the mining site. For this purpose, Rocsciense's software Dips 5.0 was used.
\end{abstract}

Keywords: Slake durability index, failure mechanisms, strength parameters. 


\section{Introdução}

O Quadrilátero Ferrífero - Minas Gerais é uma região bastante interessante para o estudo de estabilidade de taludes, devido à presença de rochas com alto grau de fraturamento, de significativas descontinuidades estruturais e de espessos perfis de alteração. Tal presença leva à ocorrência de problemas geotécnicos. Essas características, aliadas ao clima tropical úmido, marcado pelas chuvas intensas, aceleram os processos de alteração das rochas, diminuindo sua resistência e durabilidade com o tempo.

O intemperismo e a própria extração de um bem mineral podem induzir mudanças nas propriedades físicas das rochas, tais como os seus parâmetros de resistência. Essa mudança na resistência em curto prazo é denominada durabilidade e esse parâmetro pode ser definido através de um índice de durabilidade, (Gökceoglu et al., 2000), utilizado para predizer a deterioração potencial da durabilidade dos materiais, sob influência dos processos intempéricos.

A American Association for Testing and Materials (ASTM, 1990) define durabilidade, para rochas ornamentais, como sendo a medida da capacidade da referida rocha de manter as características essenciais e distintivas de estabilidade, resistência à degradação em que a rocha pode manter suas características, em uso, num determinado tempo. Esse tempo poderá ser maior ou menor e irá depender do ambiente e do uso da rocha em questão.

De forma análoga, o conceito de durabilidade pode ser aplicado no estudo de estabilidade de taludes constituídos por rochas brandas. No contexto, tal propriedade pode ser definida como sendo a resistência apresentada pela rocha à atuação dos processos intempéricos, que podem ser intensificados ou não pela ação antrópica. A durabilidade pode, dessa forma, auxiliar na caracterização dos materiais rochosos, principalmente aqueles que estão expostos na face do talude, onde alterações físico-químicas são intensas.

No caso dos filitos existentes no Talude Oeste da Mina Pau Branco, pertencente à V \& M, a ocorrência de fraturamento acentuado e dobramentos, aliados ao clima regional, leva à formação de rochas com baixa resistência, fato este que favorece os mecanismos de instabilização.

Ressalta-se que a durabilidade é uma propriedade intrínseca do material e está condicionada às propriedades físicas e químicas inerentes à mineralogia da rocha e às alterações preexistentes. Trata-se de um importante parâmetro de engenharia, especialmente no que se refere a obras envolvendo rochas de baixa resistência.

\section{Materiais e métodos}

\section{Caracterização da área - Mina Pau Branco}

A Mina Pau Branco, pertencente ao Grupo V\&M, constituída por frentes de lavra de minério de ferro, situa-se a aproximadamente $23 \mathrm{~km}$ da cidade de Brumadinho. Seu acesso é feito pela BR-040, a $30 \mathrm{~km}$ da capital Belo Horizonte.

A região está inserida na porção sudoeste do Quadrilátero Ferrífero e o minério de ferro extraído na Mina Pau Branco está entre os mais ricos do mundo, devido à localização privilegiada da zona de extração, na serra da Moeda, particularmente no flanco ocidental do sinclinal da Moeda. A Empresa extrai e beneficia três tipos de minérios de ferro: hematita, goethita e itabirito.

As rochas da Mina Pau Branco pertencem aos Grupos Itabira e Caraça, Supergrupo Minas, sendo que a zona mineralizada da mina situa-se na Formação

\section{Índices físicos}

Os índices físicos das rochas determinados em laboratório auxiliam na sua caracterização e classificação. Nesse trabalho, foram obtidos os seguintes índices físicos:

- Massa específica dos grãos $\mathrm{G}_{\mathrm{S}}$
(ABNT, NBR 6508, 1984).

- Peso específico natural $(\gamma)$.

- Peso específico seco $\left(\gamma_{\mathrm{d}}\right)$.

- Índice de vazios (e).

- Porosidade (n).

Os referidos índices físicos foram

\begin{tabular}{c|c}
\hline Grau de alteração & Descrição \\
\hline W1 & Rocha sã \\
\hline W2 & Rocha pouco alterada \\
\hline W3 & Rocha moderadamente alterada \\
\hline W4 & Rocha muito alterada \\
\hline W5 & Rocha completamente alterada \\
\hline W6 & Solo residual \\
\hline
\end{tabular}

Cauê, sobreposta ao filito da Formação Batatal.

$\mathrm{O}$ presente estudo deu enfoque aos filitos sericíticos e dolomíticos existentes no Talude Oeste da Mina, os quais apresentam, de forma geral, elevados graus de alteração e baixa resistência. As Tabelas 1 e 2 apresentam, respectivamente, os graus de alteração e de resistência utilizados na classificação de materiais rochosos, segundo ISRM, 1981.

determinados antes e após execução dos ensaios de durabilidade ("Slake Durability Test"), no intuito de verificar quais propriedades são influenciadas pelo referido ensaio.

Tabela 1

Graus de alteração das rochas (adaptado de ISRM, 1981). 


\section{Tabela 2 \\ Graus de resistência das rochas \\ (adaptado de ISRM, 1981).}

\begin{tabular}{c|c|c}
\hline $\begin{array}{c}\text { Grau de } \\
\text { resistência }\end{array}$ & Descrição & $\begin{array}{c}\text { Resistência uniaxial } \\
\text { estimada (MPa) }\end{array}$ \\
\hline R0 & $\begin{array}{c}\text { Extremamente branda e solos estruturados, } \\
\text { coesivos, rijos a duros }\end{array}$ & $0.25-1.0$ \\
\hline R1 & Rocha muito branda & $1.0-5.0$ \\
\hline R2 & Rocha branda & $5.0-25.0$ \\
\hline R3 & Rocha medianamente resistente & $25.0-50.0$ \\
\hline R4 & Rocha resistente & $50.0-100.0$ \\
\hline R5 & Rocha muito resistente & $100.0-250.0$ \\
\hline R6 & Rocha extremamente resistente & $>250.0$ \\
\hline
\end{tabular}

\section{Levantamento de estruturas geológicas}

Foi feito o levantamento das estruturas geológicas nos taludes de interesse. Nesses taludes, foram definidos pontos de amostragem para realização de ensaios de durabilidade. Análises cinemáticas, nesses pontos de amostragem, foram realizadas, de modo a definir um possível mecanismo de ruptura, segundo as descontinuidades, em cada um desses locais.
Em alguns destes locais, mesmo quando a análise cinemática prevê um modo de ruptura pelas descontinuidades, verificou-se que a ruptura se dava pelo material. Evidentemente, são locais onde o material rochoso possui grau de alteração acentuado e, portanto, baixa resistência.

Os resultados das análises cinemáticas foram confrontados com os resultados dos ensaios de durabilidade, de modo a verificar se, naqueles locais, onde a ruptura se dá pela rocha, a durabilidade seria um índice capaz de prever esse modo de ruptura, já que o grau de alteração e mesmo o grau de resistência são parâmetros bem mais subjetivos. Já o índice de durabilidade é representado por faixas de valores e sua obtenção é simples e objetiva.

\section{Ensaio de durabilidade ("Slake Durability Test")}

O ensaio de durabilidade (SDT) consistiu em submeter dez fragmentos de rocha, cada um pesando entre 40 e $60 \mathrm{~g}$, a dois ciclos normalizados de secagem e umidificação, de dez minutos cada um, além da ação mecânica. Os fragmentos são colocados dentro de redes metálicas cilíndricas com $2 \mathrm{~mm}$ de abertura, parcialmente imersos na água, girando a uma velocidade de $20 \mathrm{rpm}$, em torno de um eixo horizontal. O choque dos fragmentos de rocha entre si e o contato com a água favorecem a sua desagregação e alteração. A secagem dos fragmentos é realizada em estufas. Após esse processo, pode-se seguir outra umidificação e ação mecânica.

$O$ índice de durabilidade $\left(\mathrm{Id}_{2}\right)$ corresponde à percentagem de rocha seca que fica retida nos tambores de rede metálica em dois ciclos completos de umidificação e secagem.

Para os ensaios de durabilidade, foram selecionadas amostras de filitos do Talude Oeste da Mina Pau Branco, no intuito de avaliar a influência da dura- bilidade nos parâmetros geotécnicos dos materiais, bem como nos mecanismos de ruptura que ocorreram no talude. As amostras foram preparadas de acordo com ISRM (1979) e ASTM (1990).

O croqui e a foto do equipamento para o ensaio de durabilidade são apresentados nas Figuras 1 e 2, respectivamente. $\mathrm{O}$ índice de durabilidade é determinado através da relação entre as massas final e inicial do ensaio e é expresso através da relação apresentada na Equação 1.

$$
\text { Slake Durability Index }\left(\operatorname{Id}_{2}\right)=\frac{B-C}{A-C} \times 100 \%
$$

Onde:

A - peso seco inicial da amostras mais cilindro.
B - peso seco após o segundo ciclo da amostra mais cilindro. C - peso seco do cilindro.
A durabilidade do material é classificada de acordo com a Tabela 3.
Figura 1

Croqui do equipamento para ensaio de durabilidade.
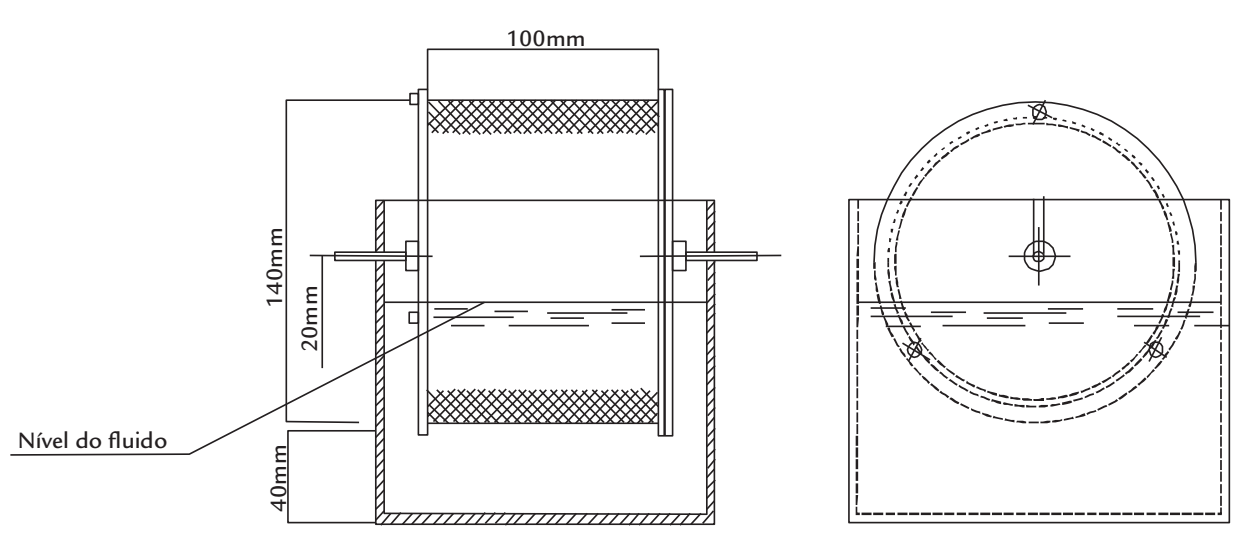


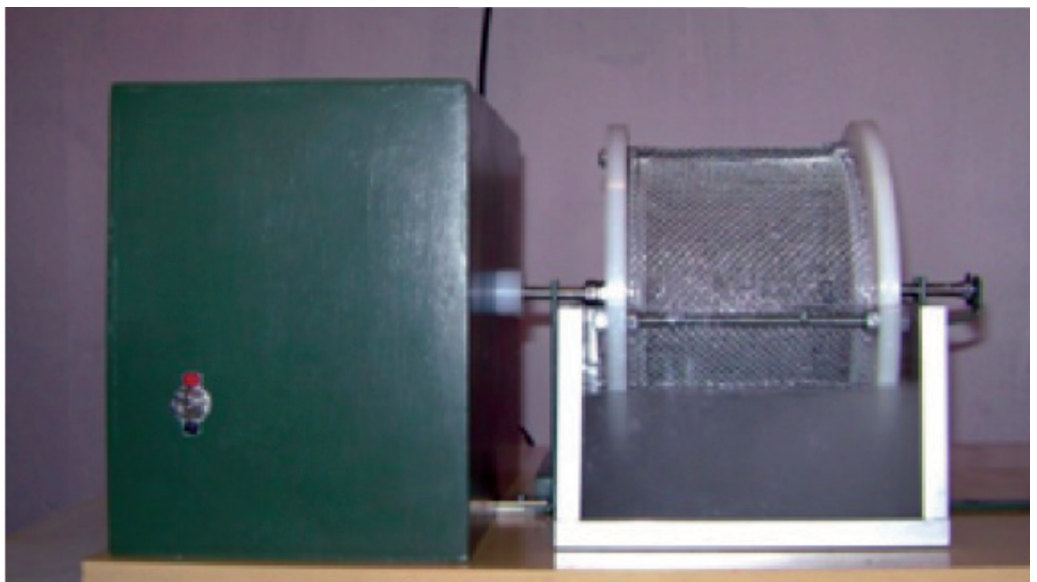

\begin{tabular}{c|c}
\hline $\mathbf{I D}_{\mathbf{2}} \mathbf{( \% )}$ & Classificação da durabilidade \\
\hline $0-25$ & Muito baixa \\
\hline $26-50$ & Baixa \\
\hline $51-75$ & Média \\
\hline $76-90$ & Alta \\
\hline $91-95$ & Muito alta \\
\hline $96-100$ & Extremamente alta \\
\hline
\end{tabular}

Figura 2

Equipamento para ensaio de durabilidade.

Tabela 3

Classificação da durabilidade (Franklin \& Chandra, 1972 in ASTM, 1990).

\section{Resultados e discussão}

\section{Índices físicos}

Os resultados obtidos, para os índices físicos, são apresentados na Tabela 4. Os ensaios de caracterização foram realizados em 8 amostras, entre filitos sericíticos (A1, A5, A6, A7 e A8) e filitos dolomíticos (A2, A3 e A4).

Verifica-se, pela Tabela 4, que houve variação de alguns índices físicos com o ensaio de durabilidade. Pode-se dizer que a redução do peso específico seco e o aumento na porosidade são reflexos da degradação provocada pela perda de material devido à percolação e ao movimento giratório durante o ensaio de durabilidade. $\mathrm{O}$ aumento da porosidade favorece a percolação de

\begin{tabular}{|c|c|c|c|c|c|c|c|c|c|}
\hline $\begin{array}{l}\text { Índices } \\
\text { físicos }\end{array}$ & $\begin{array}{c}\text { Amostra } \\
(\mathrm{W} / \mathrm{R}) \text { nota } 1\end{array}$ & $\begin{array}{c}\text { A1 } \\
\text { (W3/R2) }\end{array}$ & $\begin{array}{c}\text { A2 } \\
\text { (W3/R2) }\end{array}$ & $\begin{array}{c}\text { A3 } \\
\text { (W4/R1) }\end{array}$ & $\begin{array}{c}\text { A4 } \\
\text { (W2/R2) }\end{array}$ & $\begin{array}{c}\text { A5 } \\
\text { (W4/R0) }\end{array}$ & $\begin{array}{c}\mathrm{A6} \\
\text { (W2/R2) }\end{array}$ & $\begin{array}{c}\text { A7 } \\
\text { (W3/R3) }\end{array}$ & $\begin{array}{c}\text { A8 } \\
\text { (W2/R4) }\end{array}$ \\
\hline \multirow{2}{*}{$G_{s}$} & Antes & 2,75 & 2,79 & 2,70 & 2,80 & 2,69 & 2,79 & 2,77 & 2,78 \\
\hline & Após & 2,75 & 2,79 & 2,69 & 2,80 & 2,65 & 2,79 & 2,77 & 2,78 \\
\hline $\begin{array}{c}\gamma \\
\left(k N / m^{3}\right)\end{array}$ & - & 20,02 & 20,69 & 19,10 & 22,98 & 18,95 & 22,04 & 21,54 & 22,65 \\
\hline \multirow{2}{*}{$\begin{array}{c}\gamma_{d} \\
\left(k N / m^{3}\right)\end{array}$} & Antes & 18,98 & 19,65 & 18,12 & 22,05 & 16,98 & 21,14 & 21,01 & 21,80 \\
\hline & Após & 18,65 & 19,12 & 17,44 & 21,74 & 15,69 & 20,66 & 20,58 & 21,35 \\
\hline \multirow{2}{*}{ n (\%) } & Antes & 30,98 & 29,57 & 32,89 & 21,25 & 36,88 & 24,23 & 24,15 & 21,58 \\
\hline & Após & 32,18 & 31,47 & 35,17 & 22,36 & 40,79 & 25,95 & 25,70 & 23,20 \\
\hline & Antes & 0,45 & 0,42 & 0,49 & 0,27 & 0,58 & 0,32 & 0,32 & 0,28 \\
\hline & Após & 0,47 & 0,46 & 0,54 & 0,29 & 0,69 & 0,35 & 0,35 & 0,30 \\
\hline
\end{tabular}

(W/R) - grau de alteração/grau de resistência.

\section{Ensaios de durabilidade e análises cinemáticas}

Os resultados do ensaio de durabilidade e das análises cinemáticas são apresentados na Tabela 5. O índice de durabilidade é dado pelo resultado do $2^{\circ}$ ciclo, conforme ISRM (1979) e ASTM (1990). Nessa tabela, são também apresentadas as classificações dos materiais quanto aos graus de alteração e resistência, segundo
ISRM (1981). No total, foram realizados 20 testes de durabilidade.

$\mathrm{Na}$ Tabela 5, pode-se observar que, de forma geral, obtiveram-se índices de durabilidade menores para rochas com maior grau de alteração e menor resistência.

Para ilustrar a relação existente entre o índice de durabilidade e o modo água na rocha, o que, consequentemente, favorecerá sua desintegração com o tempo, influenciando, assim, na estabilidade do maciço rochoso.

Ressalta-se que a pequena variação nos índices físicos é devida ao pequeno número de ciclos a que as amostras foram submetidas.

\section{Tabela 4}

Índices físicos obtidos para os filitos dos pontos de amostragem $\mathrm{A} 1$ a $\mathrm{A} 8$, antes e após realização do ensaio de durabilidade.

de ruptura, os resultados dos pontos de amostragem A1 e A5 serão discutidos em detalhe.

$\mathrm{Na}$ Figura 3, a análise cinemática prevê a ocorrência de ruptura em cunha segundo as descontinuidades F1 e F2, no ponto de amostragem A1. A Figura 4 mostra que esse mecanismo de ruptura 
Tabela 5

Panorama das propriedades obtidas nos pontos de amostragem.

realmente ocorre nesse local. O índice de durabilidade é de $86,18 \%$, o que representa alta durabilidade.

Já a análise cinemática na Figura 5 ilustra o modo de ruptura por flambagem, no ponto de amostragem A5, mas a ruptura ocorre pelo material, conforme mostrado na Figura 6. Mesmo com a presença marcante da descontinuidade de foliação, a ruptura ocorre sem controle estrutural. $\mathrm{O}$ índice de durabilidade é igual a $1,89 \%$, representando

\begin{tabular}{c|c|c|c|c|c}
\hline Amostra & $\begin{array}{c}\text { Litologia } \\
\text { (Filito) }\end{array}$ & $\begin{array}{c}\text { Id }_{\mathbf{2}} \text { médio } \\
(\%)\end{array}$ & $\begin{array}{c}\text { Classificação } \\
\text { da durabilidade }\end{array}$ & $\begin{array}{c}\text { Ruptura esperada } \\
\text { (cinemática) }\end{array}$ & $\begin{array}{c}\text { Ruptura } \\
\text { ocorrida }\end{array}$ \\
\hline A1 (W3/R2) & Sericítico & 86,18 & Alta & Cunha & Cunha \\
\hline A2 (W3/R2) & Dolomítico & 47,78 & Baixa a média & Planar & Planar \\
\hline A3 (W4/R1) & Dolomítico & 26,78 & Baixa & Flambagem & Circular \\
\hline A4 (W2/R2) & Dolomítico & 87,96 & Alta & Flambagem & Flambagem \\
\hline A5 (W4/R0) & Sericítico & 1,89 & Muito baixa & Flambagem & Circular \\
\hline A6 (W2/R2) & Sericítico & 90,36 & Muito alta & - & - \\
\hline A7 (W3/R3) & Sericítico & 54,32 & Média & Flambagem & - \\
\hline A8 (W2/R4) & Sericítico & 91,56 & Muito alta & - & - \\
\hline
\end{tabular}

a classe de durabilidade muito baixa. Nesse caso, a durabilidade muito baixa é um indicador de que a ruptura ocorrerá pelo material, enquanto que a alta durabilidade do material, no ponto de amostragem A1, aponta para a impossibilidade de uma ruptura pela rocha. Nesse caso, a análise cinemática indicou o mecanismo de ruptura.

Nos pontos de amostragem A6 e A8, a durabilidade é muito alta e as análises cinemáticas não apontaram para nenhum modo de ruptura. Isso indica uma situação de estabilidade, conforme comprovado em campo.

De um modo geral, quando o índice de durabilidade é de muito baixo a baixo, seria um indício de ruptura pelo material, mesmo em caso de existência de condições cinemáticas para a ruptura. Índices de durabilidade altos ou médios apontariam para a ocorrência de ruptura com controle estrutural, caso existam condições cinemáticas favoráveis.
Figura 3

Análise cinemática, ponto de amostragem A1.

Figura 4

Ruptura em cunha, ponto de amostragem A1.
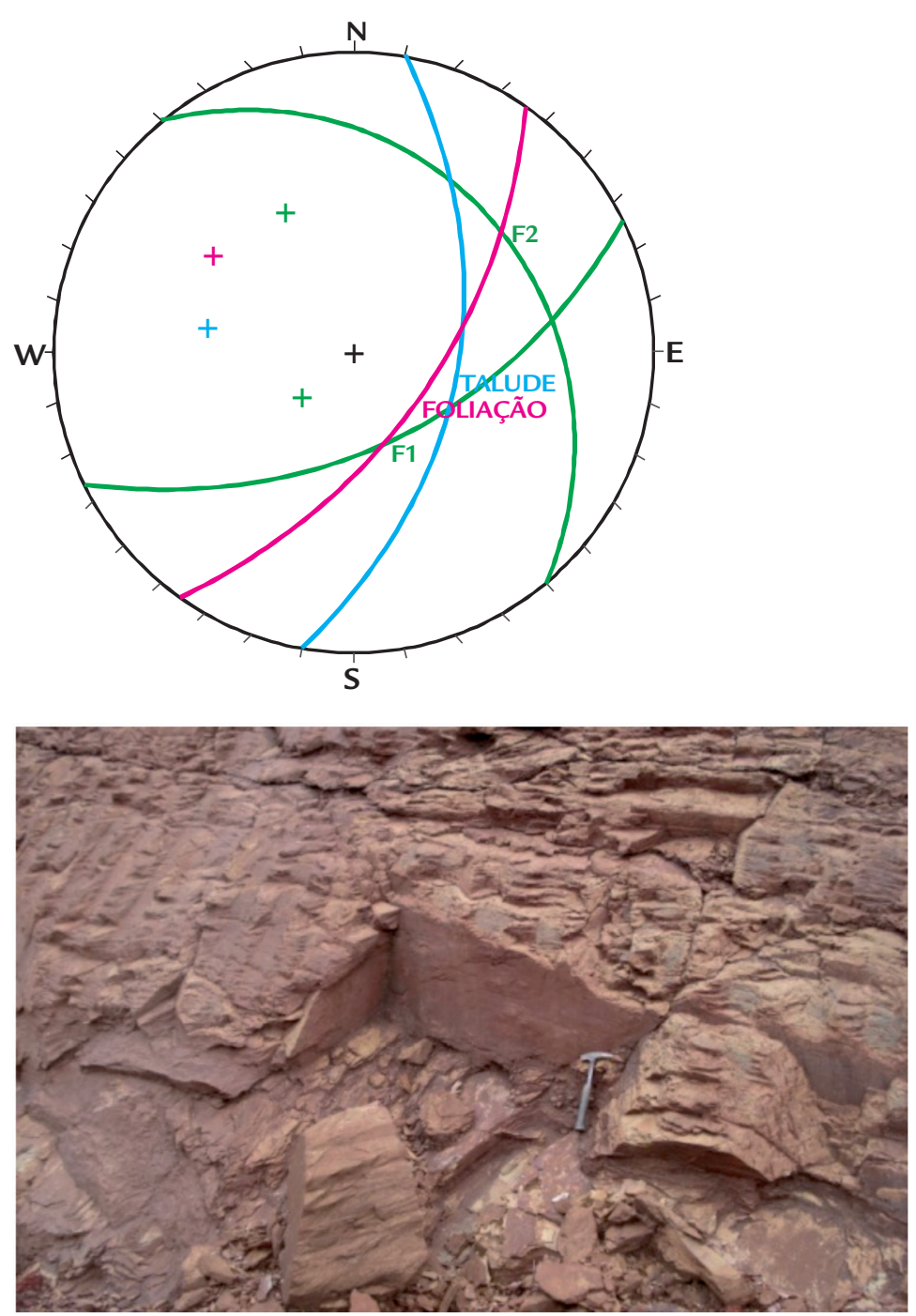

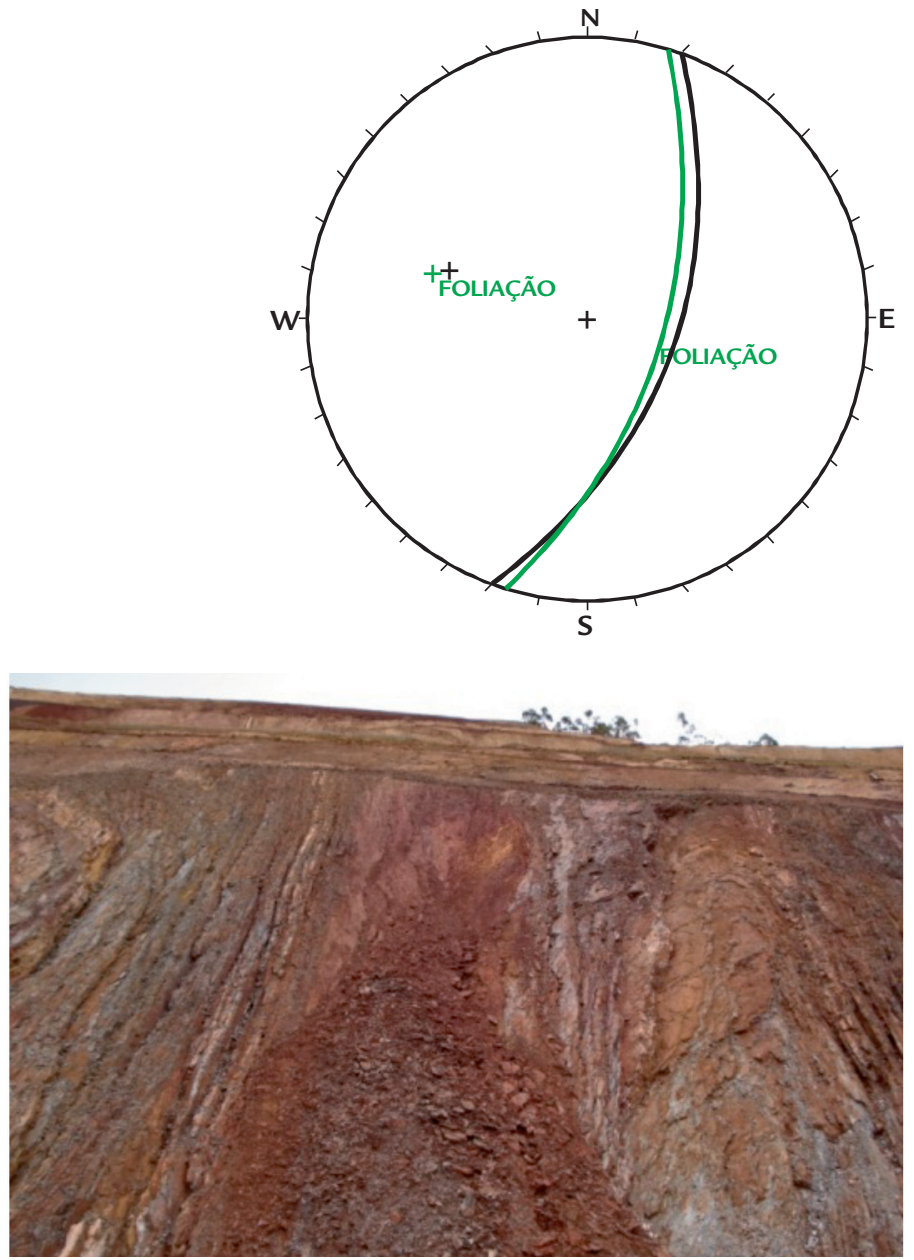

Figura 5

Análise cinemática, ponto de amostragem A5.

Figura 6

Ruptura pelo material, ponto de amostragem A5.

\section{Conclusões}

Através dos ensaios de durabilidade, foi possível verificar que o índice de durabilidade apresenta relação com as propriedades de resistência e alteração dos filitos do Talude Oeste.

A variação dos índices físicos com o ensaio de durabilidade constitui importante indicador do processo de alteração experimentado pelas rochas, o que, consequentemente, influencia na resistência do maciço, com a rocha sen- do degradada tanto pela ação da água, quando pela ação mecânica a que esta é submetida.

$\mathrm{O}$ índice de durabilidade pode ser útil para prever se a ruptura se dará pela rocha intacta ou pela estrutura geológica, o que contribui para a definição da metodologia de análise de estabilidade. Se o índice de durabilidade $\left(\mathrm{Id}_{2}\right)$ for alto, espera-se que as rupturas ocorram segundo estruturas; caso contrário, com um $\mathrm{Id}_{2}$ baixo, espera-se que a ruptura ocorra pela própria rocha. Tal fato é confirmado quando se observa os processos de instabilização nos taludes do Lado Oeste da mina.

Estudos mais detalhados poderiam estabelecer correlações muito interessantes entre o índice de durabilidade e o modo de ruptura do maciço, confirmando a tendência observada nesse trabalho.

\section{Referências bibliográficas}

ABNT NBR 6508 - Grãos que passam na peneira \# 4,8mm, determinação da massa específica. 1984. 8p.

ASTM D4644 - 08 - Standard test method for slake durability of shales and similar weak rocks. $1990.7 \mathrm{p}$.

GÖKCEOLU, C., ULUSAY R., SÖNMEZ, H. Factors affecting the durability of selected weak and clay-bearing rocks from Turkey, with particular emphasis on the influence of the number of drying and wetting cycles. Engineering Geology, v. 57, p. 215-237, 2000.

ISRM. Suggested method for determining water content, porosity, density, absorption and related properties and swelling and slake durability index properties, 1979, p. 81-94.

ISRM. Rock characterization testing and monitoring. E.T.Brown, 1981. 211p.

Artigo recebido em 18 de junho de 2010. Aprovado em 31 de maio de 2012. 